\title{
Non-incidental Concomitancy of Gastric and Duodenal Ulcers
}

\author{
Takashi Kitabatake, Shigeki Kurokawa, Mrnoru Sato, \\ Michio Yokoyama and Yoshiro Furuya* \\ Department of Radiology, Niigata University School of \\ Medicine, Niigata, and Department of Radiology,* Kyorin \\ University School of Medicine, Tokyo
}

\begin{abstract}
Kitabatake, T., Kurokawa, S., Sato, M., Yokoyama, M. and Furuya, Y. Non-incidental Concomitancy of Gastric and Duodenal Ulcers. Tohoku J. exp. Med, 1972, 107 (1), 23-29_- Based on 4,247 X-ray examinations of the upper gastrointestinal tract in the Department of Radiology, Niigata University, concomitant gastric and duodenal ulcers were analyzed statistically. The frequency of gastric ulcer among patients with duodenal ulcer is higher than that among patients with other than duodenal ulcer, with a statistical significant difference. This fact indicates that coexistence of gastric and duodenal ulcers is not incidental. $\longrightarrow$ peptic ulcer; concomitant ulcers
\end{abstract}

Gastric ulcer could be sometimes seen in one and the same patient with duodenal ulcer, which is usually called as concomitant ulcers. Concomitant gastric and duodenal ulcers have been studied pathologically, radiologically and clinically by many authors. However, it is not necessarily clear, even at present, whether concomitant ulcers incidentally occurred or not. This paper deals with a comparison between the incidence of gastric ulcer among patients who are known to have duodenal ulcer beforehand and that of gastric ulcer among general patients whose $\mathrm{X}$-ray findings are not known before fluoroscopic examination.

\section{Method and Results}

Materials: In about two years from January 1968 to October $1969,4,247$ upper gastrointestinal examinations were performed in the Department of Radiology, Niigata University. Repeated and follow-up studies were not included in this number. Therefore, the number of 4,247 represents the real number of patients who received X-ray examination of the upper gastrointestinal tract during this period. Of 4,247 cases, 259 had gastric ulcer, 239 had duodenal ulcer, and 42 had concomitant gastric and duodenal ulcers. Then, duodenal ulcer was seen in total of 281 cases. In this paper, the term "ulcer" means both active ulcer and inactive scar tissue recognized by $\mathrm{X}$-ray examination.

Sex and age distribution: The sex ratio of all patients other than with

Received for publication, September 16, 1971. 


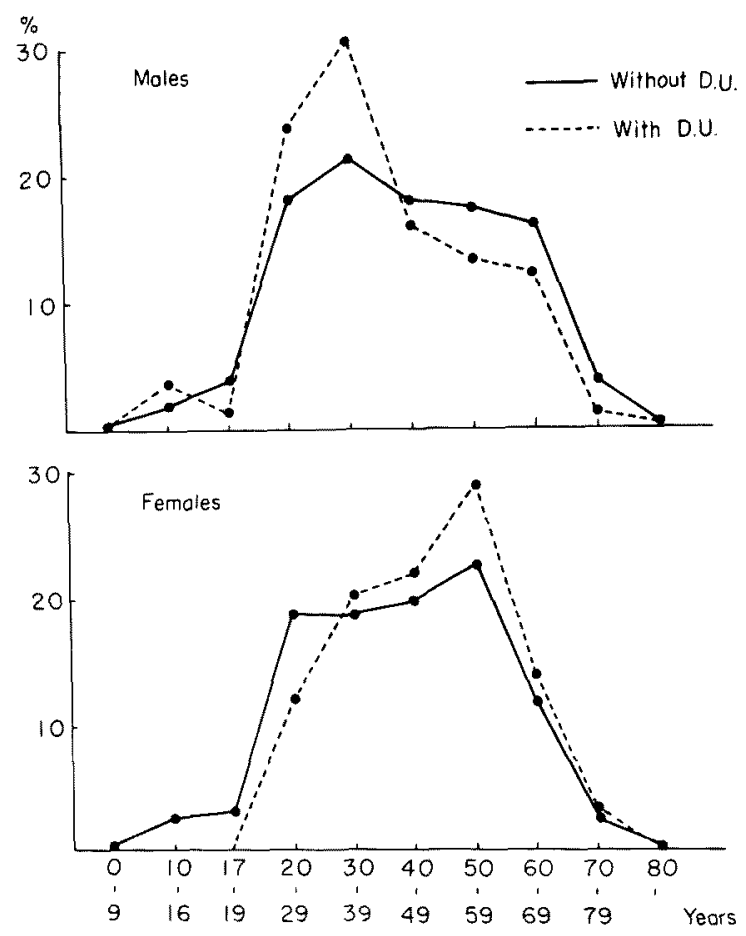

Fig. 1. Comparison of age distribution between patients with duodenal ulcer and those without duodenal ulcer.

duodenal ulcer was $\mathrm{M}: \mathrm{F}=55: 45$, which is nearly the same as that of all outpatients in the most radiodiagnostic laboratories. On the other hand, the sex ratio of 281 patients with duodenal ulcer was approximately $\mathrm{M}: \mathrm{F}=80: 20$, which is much different from that of all patients. The age distribution of these two groups is shown in Fig. 1. This also does not coincide with each other. Therefore, the incidence of gastric ulcer in these two groups cannot be directly compared, because the incidence of peptic ulcer generally varies in different sex and age groups.

Selection of control group: For the reason above described, a control group with suitable characteristics was selected. A survey group consisted of actual 281 cases of duodenal ulcer including concomitant gastric and duodenal ulcers, which we called the "duodenal ulcer group". A control group was selected from all patients other than those with duodenal ulcer, so as to give the same sex and age distribution as in the duodenal ulcer group. We called this group the "control group". A working procedure of making the control group was as follows:

a. All patients were divided into each sex and age group.

b. Individuals in each stratum were numbered from one. For example, there were 50 individuals in a stratum of actual male patients other 
TALBE 1. Calculation procedure of making the control group

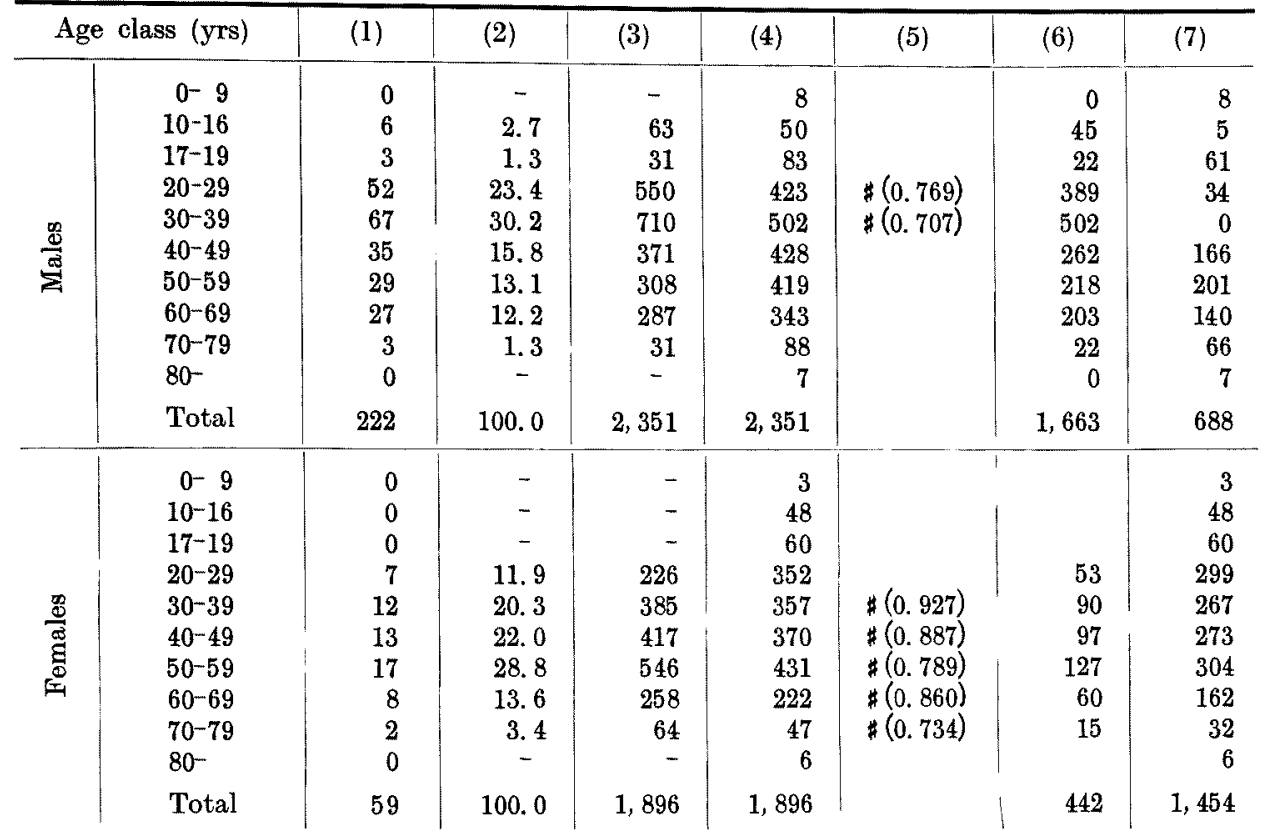

Note: The meaning of each column is as follows.

(1) Number of individuals in the duodenal ulcer group.

(2) Relative age distribution of the duodenal ulcer group.

(3) Proportionally divided number of all patients without duodenal ulcer to values of (2).

(4) Actual distribution of all patients without duodenal ulcer.

(5) Comparison of (3) and (4). The mark indicates the stratum in which the actual number (4) is less than the proportional number (3). The shortage rate is shown within the parenthesis. The maximum shortage rate is 0.707 .

(6) Number of column (3) is multiplied by 0.707 . The distribution shown in column (6) is the same as that in column (1) or (2). In females, the multiplier is 0.734 , and the ratio of male to female, 0.318 , is also multiplied. Therefore, in females the actual multiplier is 0.233 .

(7) Number to be omitted randomly from all patients in column (4). Individuals in column (6) constitute the control group.

than with duodenal ulcer aged 10 to 16 , and they were numbered from one to 50 .

c. Individuals in the duodenal ulcer group were classified after sex and age, as shown in detail in column (1) of Table 1.

d. Relative age distribution of the duodenal ulcer group is shown in column (2) of Table 1.

$e$. If the age distribution in all patients was the same as that in the duodenal ulcer group, the frequency would become as listed in column (3).

$f$. However, the actual frequency of age distribution in all patients did not coincide with that in column (3), as can be seen from column (4). 
TABLE 2. Details of the control group

\begin{tabular}{c|r|r|r|r|r|r|r|r|r}
\hline & \multicolumn{3}{|c|}{ Males } & \multicolumn{3}{c|}{ Females } & \multicolumn{3}{c}{ Both } \\
\cline { 2 - 9 } Age & $\begin{array}{c}\text { Without } \\
\text { G.U. }\end{array}$ & $\begin{array}{c}\text { With } \\
\text { G.U. }\end{array}$ & Total & $\begin{array}{c}\text { Without } \\
\text { G.U. }\end{array}$ & $\begin{array}{c}\text { With } \\
\text { G.U. }\end{array}$ & Total & $\begin{array}{c}\text { Without } \\
\text { G.U. }\end{array}$ & $\begin{array}{c}\text { With } \\
\text { G.U. }\end{array}$ & Total \\
\hline $0-9$ & & & & & & & & & \\
$10-16$ & 44 & 1 & 45 & & & & 44 & 1 & 45 \\
$17-19$ & 20 & 2 & 22 & & & & 20 & 2 & 22 \\
$20-29$ & 370 & 19 & 389 & 53 & & 53 & 423 & 19 & 442 \\
$30-39$ & 452 & 50 & 502 & 83 & 7 & 90 & 535 & 57 & 592 \\
$40-49$ & 237 & 25 & 262 & 89 & 8 & 97 & 326 & 33 & 359 \\
$50-59$ & 191 & 27 & 218 & 123 & 4 & 127 & 314 & 31 & 345 \\
$60-69$ & 178 & 25 & 203 & 57 & 3 & 60 & 235 & 28 & 263 \\
$70-79$ & 21 & 1 & 22 & 14 & 1 & 15 & 35 & 2 & 37 \\
$80-$ & & & & & & & & & \\
\hline Total & 1,513 & 150 & 1,663 & 419 & 23 & 442 & 1,932 & 173 & 2,105
\end{tabular}

G.U.: Gastric ulcer

TABLE 3. Details of the duodenal ulcer group

\begin{tabular}{r|r|r|r|r|r|r|r|r|r}
\hline & \multicolumn{3}{|c|}{ Males } & \multicolumn{3}{c|}{ Females } & \multicolumn{3}{c}{ Both } \\
\cline { 2 - 9 } Age & $\begin{array}{c}\text { Without } \\
\text { G.U. }\end{array}$ & $\begin{array}{c}\text { With } \\
\text { G.U. }\end{array}$ & Total & $\begin{array}{c}\text { Without } \\
\text { G.U. }\end{array}$ & $\begin{array}{c}\text { With } \\
\text { G.U. }\end{array}$ & Total & $\begin{array}{c}\text { Without } \\
\text { G.U. }\end{array}$ & $\begin{array}{c}\text { With } \\
\text { G.U. }\end{array}$ & Total \\
\hline $0-9$ & & & & & & & & & \\
$10-16$ & 5 & 1 & 6 & & & & 5 & 1 & 6 \\
$17-19$ & 3 & & 3 & & & & 3 & & 3 \\
$20-29$ & 48 & 4 & 52 & 6 & 1 & 7 & 54 & 5 & 59 \\
$30-39$ & 57 & 10 & 67 & 11 & 1 & 12 & 68 & 11 & 79 \\
$40-49$ & 31 & 4 & 35 & 9 & 4 & 13 & 40 & 8 & 48 \\
$50-59$ & 24 & 5 & 29 & 15 & 2 & 17 & 39 & 7 & 46 \\
$60-69$ & 20 & 7 & 27 & 7 & 1 & 8 & 27 & 8 & 35 \\
$70-79$ & 2 & 1 & 3 & 1 & 1 & 2 & 3 & 2 & 5 \\
$80-$ & & & & & & & & & \\
\hline Total & 190 & 32 & 222 & 49 & 10 & 59 & 239 & 42 & 281
\end{tabular}

g. By comparing with the values in column (3), the smallest relative frequency of individuals in column (4) is seen in the 30-39 years group, which is only $70 \%$ of the value given in column (3).

$h$. Therefore, to utilize all individuals in this class as controls, 0.707 times of values in column (3), being tabulated in column (6), should be chosen randomly from individuals in column (4). Namely, if the number of individuals as controls is chosen so as to agree to that in column (6), it would become a statistically satisfactory control group with the least uselessness.

$i$. For this purpose, the number of individuals in column (7) was taken off by a random dice from the number in column (4).

$j$. The same calculations applied for females are shown in the lower half of Table 1. 
TABLE 4. $2 \times 2$ Table for chi-square calculation

\begin{tabular}{c|c|c|c}
\hline & With gastric ulcer & Without gastric ulcer & Total \\
\hline Duodenal ulcer group & $42(14.9 \%)$ & 239 & 281 \\
Control group & $173(8.2 \%)$ & 1,932 & 2,105 \\
\hline Total & 215 & 2,171 & 2,386
\end{tabular}

Comparison of frequency of gastric ulcer: Thus, we had two populations available for this study. The first was the duodenal ulcer group consisting of 281 patients with duodenal ulcer seen in our department during the last two years. The second was the control group (2,105 individuals) newly chosen randomly from general patients without duodenal ulcer who visited our department for X-ray examination during the same period. The sex and age distribution just coincided with each other. The frequency of gastric ulcer was compared between these two groups. Table 4 is a $2 \times 2$ table for a chi-square calculation. In the duodenal ulcer group, 42 or $14.9 \%$ had gastric ucler. On the other hand, of 2,105 controls, 173 or $8.2 \%$ had gastric ulcer. Therefore, it is likely that gastric ulcer tends to occur in patients with duodenal ulcer rather than in patients without duodenal ulcer. Statistically, $\chi^{2}=13.69$, and d.f. $=1$, therefore $p<0.01$. It may be concluded that the frequency of gastric ulcer is definitely higher in patient with duodenal ulcer than in patients without duodenal ulcer. In other words, concomitant gastric and duodenal ulcers are not incidental.

\section{Discussion}

In the study of concomitant gastric and duodenal ulcers, a more justifiable ground is a pathogenic or biological one, which would provide bases to clarify whether or not the ulcerative lesion or the stomach itself in patient with both gastric and duodenal uclers is qualitatively different from those in patient with only gastric ucler. In 1917, Carman first described that gastric ulcer may be induced by retention of gastric contents. Since then, similar opinions have been presented by many investigators. Finally, Dragstedt (1956) has developed the socalled retention theory. Johnson (1955 and 1965) studied 130 cases of concomitant gastric and duodenal ulcers, and concluded that, (1) duodenal ulcer usually precedes, (2) gastric retention is seen in many cases, (3) pyloric stenosis is frequent, and (4) concomitant ulcers show appreciable resistance to therapeutic measure as compared with cases of single gastric ulcer. Huber and Huntington (1948) and Murray et al. (1967) also supported this theory.

On the other hand, there have been some dissents from the retention theory. In 1958, Mangold described that no gastric retention was observed in 157 cases of concomitant gastric and duodenal ulcers. Thereafter, du Plessis (1965) also observed a similar tendency, and concluded that gastric ulcer may be produced by back flow of duodenal contents to the stomach. Recently, Bateson (1969) further emphasized the back flow theory based on analysis of 1,077 cases of con- 
comitant gastric and duodenal ulcers. Reviewing a series of these papers, no unshakable pathogenesis of concomitant gastric and duodenal ulcers appears to have been established yet. Under these circumstances, a statistical consideration may be useful as a second way of investigating the pathogenesis.

In the statistical study to detect a significant difference of the frequency, two groups should be qualitatively equal except for characteristics to be compared. That is, sex, age, occupation, residence, eating habits, etc. should be as equal as possible. According to Yamagata (1970), even in Japan, the ratio of gastric ucler to duodenal ulcer becomes larger with the increase of geographic latitude. Also peptic ulcer is seen more frequently in autumn to winter than in spring and summer. Monson and MacMahon (1969) described that peptic ulcer in female physicians in Massachusetts is more frequent than in general female population. A so-called stress ulcer also tends to occur increasingly (Eiseman and Heyman 1970). These data indicate that the incidence of peptic ulcer may be much influenced by many factors. Therefore, for an accurate statistical study, it is essential to choose two groups with the same rate of these factors. However, this is actually impossible. In this paper, we paid attention to only sex and age distribution, which are the most important factors of all, and other factors than sex and age were not considered.

Secondly, all peptic ulcers are not always detectable roentgenologically. According to Yamagata and Masuda (1958), the diagnostic accuracy of peptic ucler was nearly $88 \%$ on the average in Japan from 1948 to 1955 . Similar data have been published by Prévot (1954) and Garland (1959). Summarizing these, the radiodiangostic accuracy is considered to be less than $95 \%$. Recently, 74 cases of peptic ulcer were surgically treated after X-ray examination in our department. In only $80 \%$ the $\mathrm{X}$-ray diagnosis completely coincided with surgical findings.

This raises the question as to whether $\mathrm{X}$-ray diagnosis is an adequate or sufficient method to detect peptic ulcer or not. However, generally speaking, other techniques such as duodenal fiberscope are not yet popular as a routine measure. And, analysis of concomitant gastric and duodenal ulcers has been made mainly radiologically. Therefore, also in this study diagnosis of peptic ulcer was made only by X-rays. Even for the patients who received surgical treatment or endoscopic examination, radiological diagnosis was not corrected. Nevertheless, this analysis may give some useful addition to pathogenesis of concomitant gastric and duodenal ulcers.

\section{References}

1) Bateson, E.M. (1969) Concomitant gastric and duodenal ulcers. Brit. J. Radiol., 42, 598-604.

2) Carman, R.D. (1917) Roentgen diagnosis of concurrent gastric and duodenal ulcers. Amer. J. Roentgenol., 4, 552-554.

3) Dragstedt, L.R. (1956) A concept of the etiology of gastric and duodenal ulcers. Gastroenterology, 30, 208-220

4) du Plessis, D.J. (1965) Pathogenesis of gastric ulceration. Lancet, 1, 974-978. 
5) Eiseman, B. \& Heyman, M.R.L. (1970) Stress ulcers: A continuing challenge. New Engl. J. Med. 282, 372-374.

6) Garland, L.H. (1959) Studies on the accuracy of diagnostic procedures. Amer. $J$. Roentgenol., 82, 25-38.

7) Huber, F. \& Huntington, C.G. (1948) Gastric retention and gastric ulcer. Amer. $J$. Roentgenol, 60, 80-85

8) Johnson, H.D. (1955) The special significance of concomitant gastric and duodenal ulcers. Lancet, 1, 266-270.

9) Johnson, H.D. (1965) Gastric ulcer: Classification, blood group characteristics, secretion patterns and pathogenesis. Ann. Surg., 162, 996-1004.

10) Mangold, R. (1958) Combined gastric and duodenal ulceration: A survey of 157 cases. Brit. med. J., 2, $1193-1197$.

11) Monson, R.R. \& MacMahon, B. (1969) Peptic ulcer in Massachusetts physicians. New Engl. J. Med., 281, 11-15.

12) Murray, G.F., Ballinger, W.F. \& Stanford, E.S. (1967) Ulcers of the pyloric channel. Amer. J. Surg., 113, 199-203.

13) Prévot, R. (1954) Röntgenologie der Magenkrankheit. In: Der Magen und seine Krankheiten, edited by R. Boller, Urban \& Schwarzenberg, Wien.

14) Yamagata, S. (1970) Pathogenesis and treatment of peptic ulcer. Nippon Ishikai Zasshi (Jap.), 63, 157-183.

15) Yamagata, S. \& Masuda, H. (1958) Accuracy of $X$-ray diagnoses of gastric and duodenal ulcers. Igaku no Ayumi (Jap.), 27, 131-140. 